\title{
Legacy media as inhibitors and drivers of public reservations against science: global survey evidence on the link between media use and anti-science attitudes
}

\author{
Niels G. Mede (10 ${ }^{1 \times}$
}

Public resentment toward scientific institutions, scholars, and their expertise challenges the status of science in society in many countries worldwide. It is thus essential to examine the global prevalence of such resentment-and the potential of legacy media to temper it, thanks to their ability to cultivate positive views of science, educate citizens, and connect publics to scientific discourse. However, existing research has mostly surveyed Western populations, focused on pro-science rather than anti-science views, rarely studied the role of media use, and often ignored country characteristics that may interact with media use. This secondary analysis addresses these caveats, drawing on the 2017-2020 wave of the World Values Survey ( $N=70,867$ in 49 countries) and three relevant country-level indicators (freedom of the press, populism, uncertainty avoidance). Findings indicate that anti-science attitudes vary substantially across countries and are more prevalent in many Latin American nations. Results of Bayesian multilevel regressions show that frequent use of newspapers, TV, and radio indeed alleviates anti-science attitudes in some countries-but fosters them in others, particularly in those where populist rhetoric is more prevalent in public discourse, potentially because such rhetoric often challenges science and academic expertise. These findings call for further comparative research on global reservations against science and reflections about their repercussions on the science-society nexus.

\footnotetext{
${ }^{1}$ Department of Communication and Media Research (IKMZ), University of Zurich, Andreasstrasse 15, 8050 Zurich, Switzerland.

凶email: n.mede@ikmz.uzh.ch
} 


\section{Introduction}

cross the world, science has been challenged by public reservations against it-such as preference of faith over academic expertise, moral resentment toward scientists, or disinterest in scientific knowledge (Rutjens et al., 2022). These reservations can undermine the capacity of science to effectively provide reliable knowledge for informed everyday decisions, policymaking processes, and societal discourses (Mehta et al., 2020). Public resentment toward science thus curbs its potential to help individuals and societies cope with daily challenges as well as severe environmental, health, and economic crises like climate change or the COVID-19 pandemic (Luna et al., 2021). For example, such resentment has been shown to reduce people's knowledge (Allum et al., 2008), compliance with government policies (Merkley and Loewen, 2021), or confidence in vaccination (Sturgis et al., 2021), and increase support for political movements and candidates that are skeptical of experts (Motta, 2018). Anti-science attitudes therefore pose a challenge to education, well-being, and democracy.

Public opinion researchers and science communication scholars have thus examined the prevalence of anti-science attitudes in large-scale, nationally representative population surveys, and sought ways to reduce these attitudes. On the one hand, findings suggest that reservations against science are often more widespread within certain sociodemographic and attitudinal milieus, e.g., in older, lower educated, more religious, or politically conservative subpopulations (Chan, 2018; Noy and O'Brien, 2019; Rutjens et al., 2022).

On the other hand, multiple surveys indicate that anti-science attitudes tend to be less widespread among people who frequently use newspapers, TV, or radio to inform themselves about current matters in general or scientific topics in particular (Anderson et al., 2012; Besley and Shanahan, 2005; Cacciatore et al., 2018; Dudo et al., 2011; Liu and Priest, 2009). These media, which are often termed "legacy media" (Fawzi and Krämer, 2021, p. 3293), seem to alleviate anti-science sentiment under certain conditions and to some degree-presumably because they often feature positive depictions of science, emphasize its problem-solving capacity, ascribe epistemic authority to scientists, and cultivate public understanding of the scientific research process (Brondi et al., 2021; Hilgard and Jamieson, 2017; Lee and Scheufele, 2006; Nisbet et al., 2002). More generally, legacy media can be conceived as mediators at the science-society nexus, i.e., as institutions that convey public trust in science (Schäfer, 2016). Frequent use of newspapers, TV, or radio could thus be assumed to trigger favorable orientations toward science-and temper reservations against it (see Diehl et al., 2021; Huber et al., 2019; Schäfer, 2016).

Processes like these have been conceptualized against the backdrop of concepts like framing (Brossard and Nisbet, 2007) or cultivation (Nisbet et al., 2002), which suggest that people's appreciation for science is a long-term outcome of exposure to positive media portrayals of scientists in newspaper, TV, and radio reporting, for example. Further scholarship theorized that effects like these differ across media channels, people, and countries, as they depend on individual habits, skills, or preexisting attitudes, and on the characteristics of local media systems, political contexts, or cultural conditions (Boomgaarden and Song, 2019; Valkenburg and Peter, 2013).

However, research on the prevalence of anti-science attitudes and the ability of legacy media to affect these attitudes has several limitations (see Guenther and Joubert, 2017; Massarani, 2015; Metag and Schäfer, 2018). First, it has usually examined only single countries (e.g., Hmielowski et al., 2014) and thus barely provides insights as to how prevalence and media effects compare across nations. Second, research which does include multiple countries has investigated almost exclusively Western, educated, industrialized, rich, and democratic (WEIRD) societies (e.g., Lübke, 2021; Yan et al., 2021), although certain non-WEIRD countries provide specific conditions for anti-science sentiments (Bauer et al., 2019) and exhibit distinctive media systems (Hallin and Mancini, 2011). Third, studies which do compare WEIRD and non-WEIRD societies have often examined attitudes toward specific science-related topics rather than attitudes toward science in general (Diehl et al., 2021; Franzen and Meyer, 2010; Hornsey et al., 2018a, 2018b), even if these attitudes were shown to vary across topics (Rutjens et al., 2022). Fourth, comparative surveys on public views of science in general have mostly focused on proscience views such as trust, confidence, or faith (Evans, 2014; Gil de Zúñiga et al., 2019; Kim et al., 2014; Price and Peterson, 2016; Sturgis et al., 2021; Wellcome Trust, 2019). Yet favorable and unfavorable orientations toward any kind of object cannot necessarily be conceived as polar opposites, because they may often have different qualities, antecedents, and implications, and may rather be understood as "alternative social realities" (Lewicki et al., 1998, p. 445; see also van de Walle and Six, 2014). Therefore, findings on pro-science attitudes may not apply to anti-science attitudes. Fifth, cross-cultural surveys that do investigate unfavorable science attitudes specifically have not included media use variables (Chan, 2018; Crettaz von Roten, 2019; Noy and O'Brien, 2019; Rutjens et al., 2022).

Many existing surveys nevertheless provide useful suggestions for the present study. Some are instructive because they show that individual-level attitudes toward science are moderated by country-level factors (Allum et al., 2008). However, these surveys have not considered factors related to media use but focused on socioeconomic indicators such as the GDP or the Gini coefficient (O'Brien and Noy, 2018; Sturgis et al., 2021). Others are helpful because they suggest links between legacy media use and political attitudes (Boomgaarden and Song, 2019) or between social media use and trust in science (Huber et al., 2019).

Yet overall, scholarship is inconclusive in at least two ways: First, it offers little robust evidence on the prevalence of antiscience attitudes in non-WEIRD publics. On the one hand, these publics may hold science in high esteem, hoping that it will solve existential crises immediately affecting them, such as climate change or epidemic diseases (Drori et al., 2003; Solís Arce et al., 2021). On the other hand, segments of non-WEIRD populations may be skeptical or at least indifferent about scientific research as their daily lives pose practical challenges for which they deem academic expertise less relevant or helpful (see Guenther and Weingart, 2018).

Second, it is unclear if legacy media use can weaken antiscience attitudes not only in WEIRD but also in non-WEIRD countries, whether such weakening effects vary across countriesand if there are country-level factors that explain variation. First, freedom of the press can be conceived as one such factor: Citizens' chances of encountering media portrayals of science that question its societal authority are higher in countries with free and independent media (an Nguyen and Tran, 2019). Critical public attitudes toward science or science-related issues such as nuclear energy could therefore be more widespread if media freedom is high (Kim et al., 2013). Second, the prevalence of populist rhetoric within national public discourse could moderate links between media use and anti-science attitudes: Such rhetoric often challenges academic elites and "mainstream scientists" (Forchtner et al., 2018; p. 596), suggesting that scientific knowledge is useless, ideologically biased, and inferior to the commonsensical, emotional, and experiential knowledge of "ordinary people" (Mede and Schäfer, 2020, p. 480). Media in several countries have been found to disseminate populist ideas rather uncritically and provide populists with means to spread anti-scientific claims (Adam 
et al., 2020; Thornborrow et al., 2021; Wettstein et al., 2018). Media audiences in these countries may then adopt those ideas and claims and develop critical attitudes toward science (see Müller et al., 2017). Third, uncertainty avoidance tendencies among certain cultures could affect the potential of legacy media to temper anti-science sentiment: This potential may be lower in media systems in which journalists (or audiences) are more inclined to avoid covering (or encountering) uncertainties, controversies, and ambiguities like those that science and scientific innovations entail (Ruan et al., 2019). Public support for antiscientific narratives, such as conspiracy theories, are therefore often more pronounced in societies with stronger uncertainty avoidance tendencies (Mari et al., 2021). Correspondingly, uncertainty tolerance may be associated with low public resentment toward science (Bauer and Süerdem, 2016). Concludingly, we assume that a link between legacy media use and anti-science attitudes is moderated by the following country-level factors: Freedom of the press (Freedom House, 2021), prevalence of populist rhetoric in political discourse (Norris, 2020), and uncertainty avoidance (Hofstede et al., 2010).

Overall, there is little systematic, cross-cultural survey evidence on anti-science attitudes and their relationship with legacy media use-albeit such evidence is required to make substantive claims about the global challenge that public anti-science attitudes pose to societal well-being, education, and democracy, and about the potential of legacy media to reduce these attitudes. This study addresses this caveat. It relies on a secondary analysis of survey data collected for the World Values Survey in 2017-2020, as well as three country-level indicators, and tests the following research questions and hypothesis:

RQ1: How prevalent are anti-science attitudes across countries worldwide?

H1: Anti-science attitudes are negatively associated with legacy media use.

RQ2: How does the association hypothesized in $\mathrm{H} 1$ vary across countries?

RQ3: How can national levels of press freedom, populism, and uncertainty avoidance explain the variation assumed in RQ2?

\section{Methods}

Data. We utilized nationally representative data of the World Values Survey (WVS), a large-scale, recurring survey assessing public perceptions, beliefs, and behaviors across a wide range of cultural, social, and political issues in numerous countries worldwide (Inglehart et al., 2004). We drew on the $7^{\text {th }}$ WVS wave, which was conducted from January 2017 to August 2020 and relied on face-to-face interviews ${ }^{1}$ in 49 countries on all continents (Haerpfer et al., 2020). Descriptive analyses included all 49 countries $(N=70,867$; gender: $47.4 \%$ male; age: $M=42.7$, $\mathrm{SD}=16.3)$. Inferential analyses used data from 38 of these 49 countries $(N=54,658$; gender: $47.2 \%$ male; age: $M=43.4$, $\mathrm{SD}=16.8)$, because anti-science attitudes, media use, and relevant covariates were not measured in some countries (see Supplementary Table S3 for a list of countries and country-level sample characteristics).

The WVS is a well-established extensive survey project led by experienced researchers who continuously develop its design and instruments (Haerpfer and Kizilova, 2017). Scholars from several fields, including communication studies, have used it for highly cited academic publications (e.g., Tsfati and Ariely, 2014). However, the WVS is subject to similar caveats like other comparative surveys: Difficulties include cross-national differences in sampling procedures, fieldwork periods, interviewing techniques, and questionnaire translations (Curtice, 2007; Esmer, 2004; Heath et al., 2005), as well as limited measurement invariance and external item validity (Alemán and Woods, 2016; Johnson and Mislin, 2012). We acknowledge these caveats, but we do not think that they pose major obstacles to our analyses-and emphasize that the WVS is eventually one of the best freely available sources for survey data from non-WEIRD countries currently existing (Haerpfer and Kizilova, 2017).

Moreover, we relied on three country-level indicators to measure factors that could explain why media effects vary across countries:

(1) Freedom of the press: Measured with the Freedom of the Press Index, which is annually published by the non-profit, non-governmental organization Freedom House. On a scale from 0.0 to 100.0 , it reflects the ability of domestic "print, broadcast, and digital media to operate freely and without threat of repercussions" (Freedom House, 2021; higher scores indicate more freedom; $M=57.6, \mathrm{SD}=27.2$, range within sample: 9.0-98.0). For each country, we used the score that Freedom House had assigned to it when the WVS was fielded in that country.

(2) Prevalence of populist rhetoric: Measured with a continuous index composed from two items measured in the Global Party Survey 2019, which asked 1861 experts to assess the agendas and rhetoric of 1043 political parties in 163 countries (Norris and Inglehart, 2019). To obtain this index, we proceeded as follows: First, we selected two items that asked experts how strongly each party in a given country favors populist vs. pluralist rhetoric (11-point Likert scales, $0=$ strongly favors pluralist rhetoric $10=$ strongly favors populist rhetoric) and how important populist rhetoric is for each party in that country (11-point Likert scales, $0=$ no importance $-10=$ great importance). Second, we computed mean values of these two items across all parties within each country. Third, we averaged these values, which resulted in a single aggregate measure for the prevalence of populist rhetoric within national political discourses (higher values indicate higher prevalence; $M=6.10, \mathrm{SD}=0.90$, range within sample: $4.0-8.4$ ).

(3) Uncertainty avoidance: Measured with the Uncertainty Avoidance Index, which is one of several scores Hofstede (1980) devised to quantify national cultures across the world. On a scale from -150.0 to 230.0 , it captures the degree to which citizens of a given country refrain from being exposed to ambiguity and controversy (higher values indicate higher avoidance; $M=69.8, \mathrm{SD}=21.7$, range within sample: $29.0-112.0$ ). Unlike the other two countrylevel indicators used in this study, this index is not based on expert ratings but on large-scale employee surveys-which bears certain limitations such as coverage and sampling errors (Gerlach and Eriksson, 2021), but it is arguably a more valid approach to measuring latent values within national cultures than using external expert ratings (Smith et al., 2002). We drew on the most current Uncertainty Avoidance Indices, the majority of which stem from Hofstede's original studies in 1980 (Hofstede et al., 2010).

These indicators are established measures frequently used in global comparative research (Coffé, 2017; Mari et al., 2021; Norris, 2020). Even if some scholars have legitimately argued that they ignore within-country differences, are limited in their capability to express the bandwidth of aspects they aim to grasp, and depend on certain normative ideals, they are still useful proxies for estimating country characteristics on an aggregate level (Bollen, 1980; Freudenberg, 2003). 
Measures. Anti-science attitudes were measured with a mean score of three items (10-point Likert scales, $1=$ completely disagree $-10=$ completely agree).

(1) "We depend too much on science and not enough on faith", which reflects rejection of the epistemic and cultural authority of science and preference for religious or alternative beliefs (Miller, 2004; $M=5.60, \mathrm{SD}=2.93$, range: $1-10)$.

(2) "One of the bad effects of science is that it breaks down people's ideas of right and wrong”, which captures the belief that science erodes established moral worldviews (Kam, 2005; $M=5.52, \mathrm{SD}=2.86$, range: $1-10$ ).

(3) "It is not important for me to know about science in my daily life", which taps cognitive disengagement from scientific knowledge and expertise (Evans and Durant, 1995; $M=4.58, \mathrm{SD}=2.95$, range: $1-10)$.

These items have been validated in numerous public opinion studies and are widely used survey measures for capturing three essential components of public reservations against science, i.e., (1) preference of faith over scientific expertise, (2) moral resentment toward science, and (3) disinterest in scientific knowledge (see Chan, 2018). They correlated moderately (Cronbach's $\alpha=0.54$ ) and captured one underlying concept: Multilevel Exploratory Factor Analysis implemented via multigroup Exploratory Structural Equation Modeling (ESEM; Marsh et al., 2011) indicated that they loaded on one common factor $\left(\chi^{2}=728.374, \quad \mathrm{df}=96, \quad p<0.001 ; \quad \mathrm{CFI}=0.953, \quad \mathrm{TLI}=0.929\right.$, $\mathrm{RMSEA}=0.079, \mathrm{SRMR}=0.036)$. Therefore, the resulting mean score represented a reliable measure of respondents' anti-science attitudes $(M=5.23, \mathrm{SD}=2.12$, range: $1-10)$.

Notably, the WVS also contains some items that measure proscience attitudes, e.g., "Science and technology are making our lives healthier, easier, and more comfortable" (Haerpfer et al., 2020). Single studies utilized items like these after reverse-coding them to measure reservations against science (Nisbet et al., 2002). However, we had multiple reasons not to follow this approach, as we detail in the Supplementary Material: First, pro-science and anti-science views cannot necessarily be conceptualized as opposing ends of the same continuum, hence it is problematic to equate absence of the former with presence of the latter (All European Academies, 2019; see also above). Second, existing research has shown that combining anti-science items and reverse-coded pro-science items in one aggregate score introduces artificial dimensionality into that score and lowers its validity and reliability (Mede et al., 2021; Schriesheim and Eisenbach, 1995). Third, additional analyses indicated that the three anti-science items (see above) and three reverse-coded pro-science items contained in the WVS loaded on two distinct factors (see Supplementary Table S1 and Supplementary Fig. S2) that correlated only very weakly $(r=0.01)$. Multilevel Exploratory Factor Analyses showed that a forced 1-factor solution with all these six items fitted the data much worse than a 1-factor solution that only contained the three anti-science items (see Supplementary Table S2). Eventually, including the three reverse-coded proscience items in our anti-science score did not improve its reliability (Cronbach's $\alpha$ of 3-item score: 0.54 ; Cronbach's $\alpha$ of 6-item score: 0.53 ).

Legacy media use was measured with a mean score of three items asking for how often respondents use daily newspapers, TV news, and radio news to obtain information about "what is going on in this country and the world" $(4=$ daily, $3=$ weekly, $2=$ monthly, $1=$ less than monthly, $0=$ never). Items correlated moderately (Cronbach's $\alpha=0.51$ ), which is plausible and somewhat desirable as they refer to a relatively broad scope of information sources (see Taber, 2018, who argues that reliability test statistics are not necessarily useful when evaluating scores that capture phenomena that manifest in a wide range of cognitions, attitudes, or behaviors). The resulting mean score can thus be considered a valid aggregate measure for people's legacy media use $(M=2.23, \mathrm{SD}=1.08$, range: $0-4)$.

We controlled for a set of sociodemographic and attitudinal covariates that were shown to affect public beliefs about science globally (e.g., Crettaz von Roten, 2019; O’Brien and Noy, 2018; Sturgis et al., 2021). These included gender (binary), age (in years), education (9 categories, ISCED-2011 classification), income ( $1=$ lowest income group $-10=$ highest income group), town size $(1=$ under $2000-10=500,000$ and more), religiosity ( $1=$ God not important at all $-10=$ God very important $)$, and political orientation $(1=$ left $-10=$ right $)$.

Analysis. To test our research questions and hypothesis, we fitted Bayesian regression models with the $\mathrm{R}$ package brms (Bürkner, 2021) and weakly informative priors (Nalborczyk et al., 2019). All analyses can be reproduced with the data and code we share in the Open Science Framework (OSF) at https://osf.io/w4gey. For all estimates, we will report means and $89 \%$ Highest Density Intervals (HDI) of posterior distributions (McElreath, 2020).

The prevalence of anti-science attitudes across countries (RQ1) was derived from posterior probability distributions of intercepts of 49 Bayesian null models (one for each country), each of which regressed the anti-science score on 1 . The relationship of antiscience attitudes and legacy media use (H1 and RQ2) was examined in a Bayesian multilevel model that included the antiscience score as outcome variable, media use as a predictor, and country-level varying intercepts and slopes of media use, and controlled for the sociodemographic and attitudinal covariates (Model 1). Moderators of varying media use effects (RQ3) were explored by adding cross-level interactions of media use and the three country-level indicators to Model 1 (Model 2).

We decided to employ Bayesian methods as they have a number of advantages over conventional (i.e., frequentist) approaches: For example, Bayesian analysis expresses the uncertainty about an estimate with a credible interval that can be interpreted straight-forwardly as the probability that the true value of this estimate falls within that interval. Frequentist analysis, however, allows only approximations to the uncertainty about estimates, because quantities indicating this uncertainty ( $p$ values, confidence intervals) are contingent upon the collected data. Moreover, Bayesian methods are particularly useful for cross-country studies such as ours, because they outperform frequentist methods in estimating the variances of random effects (see Scharkow, 2019). Nevertheless, we also ran frequentist versions of all analyses presented below, finding that results differed only very marginally (see replication files on OSF).

\section{Results}

RQ1 analyses showed that anti-science attitudes are, on average, moderately prevalent worldwide $(M=5.23$ on a scale from $1-10$; 89\% HDI: 5.22-5.24). However, they fluctuate considerably across countries: On the one hand, populations of many Latin American nations like Nicaragua, Bolivia, Colombia, and Mexico have higher anti-science scores (see Fig. 1; see Supplementary Figs. S3-S8 for means, standard errors, and response frequencies of individual items). On the other hand, populations of several Anglo-American and East Asian countries like Australia, Japan, the US, and China are less inclined to prefer faith over science, think science undermines moral values, and deem scientific knowledge unimportant. Yet anti-science attitudes are not necessarily more widespread in non-WEIRD nations: Indonesia and Ethiopia, for example, are among the least critical countries 


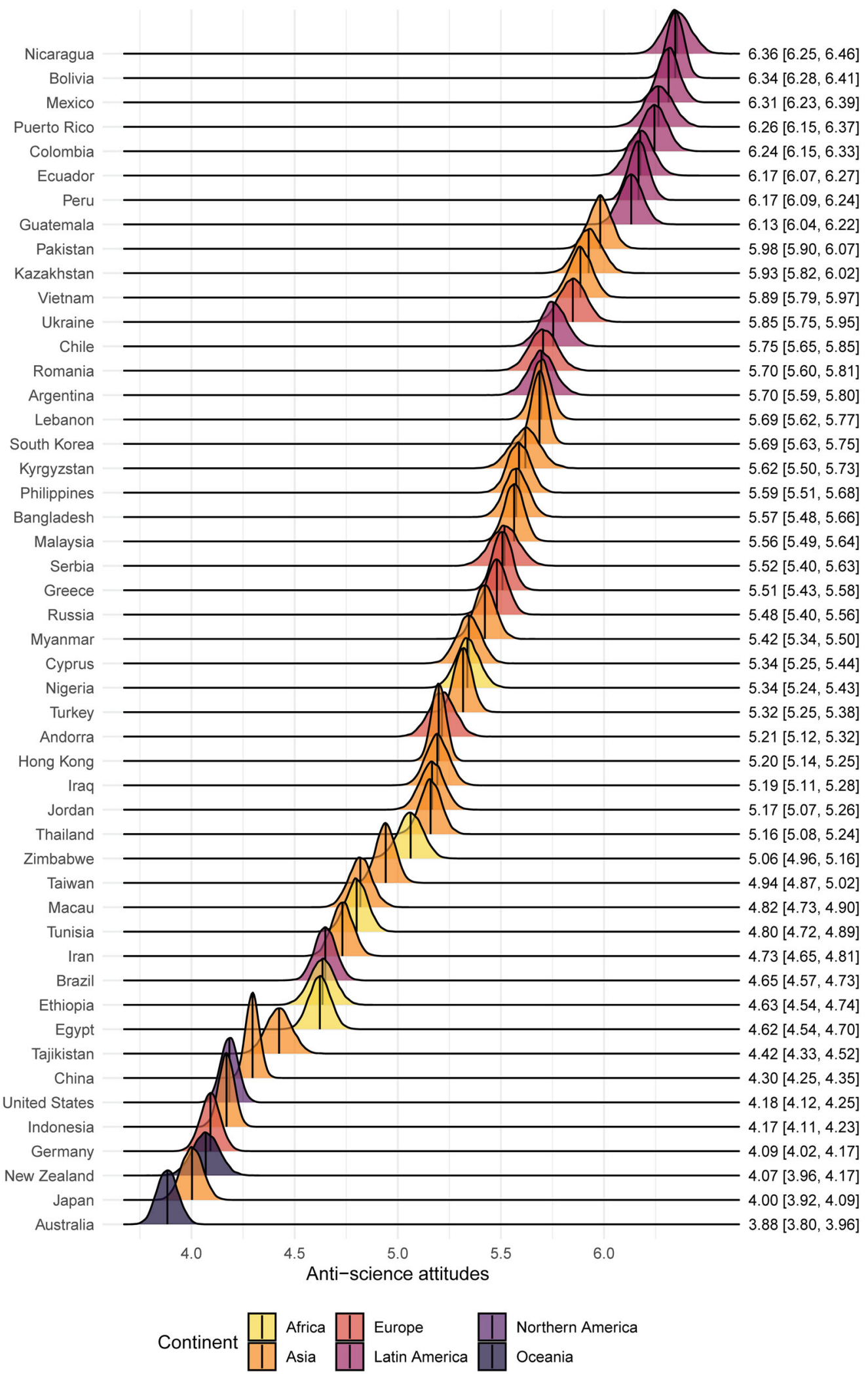

Fig. 1 Posterior probability distributions of anti-science attitudes across countries. Note: Vertical lines represent posterior probability distribution means of intercepts of Bayesian null models fitted within country subsamples. Values reported indicate distribution means as well as lower and upper bounds of $89 \%$ HDls. Intercept of Bayesian null model fitted within full sample: 5.23 [5.22, 5.24].

included in the analysis. Meanwhile, WEIRD populations vary somewhat in their views: Most tend to be less negative about science (e.g., New Zealand, the US, Germany), whereas others are more critical (e.g., Greece).
H1 tests suggested that globally, frequent use of newspapers, $\mathrm{TV}$, and radio does not weaken anti-science attitudes $(b=0.008$, 89\% HDI: $-0.032-0.048)$. Hence, in contrast to previous research on public perceptions of science, we did not find evidence for a 
Table 1 Bayesian multilevel models predicting anti-science attitudes across countries.

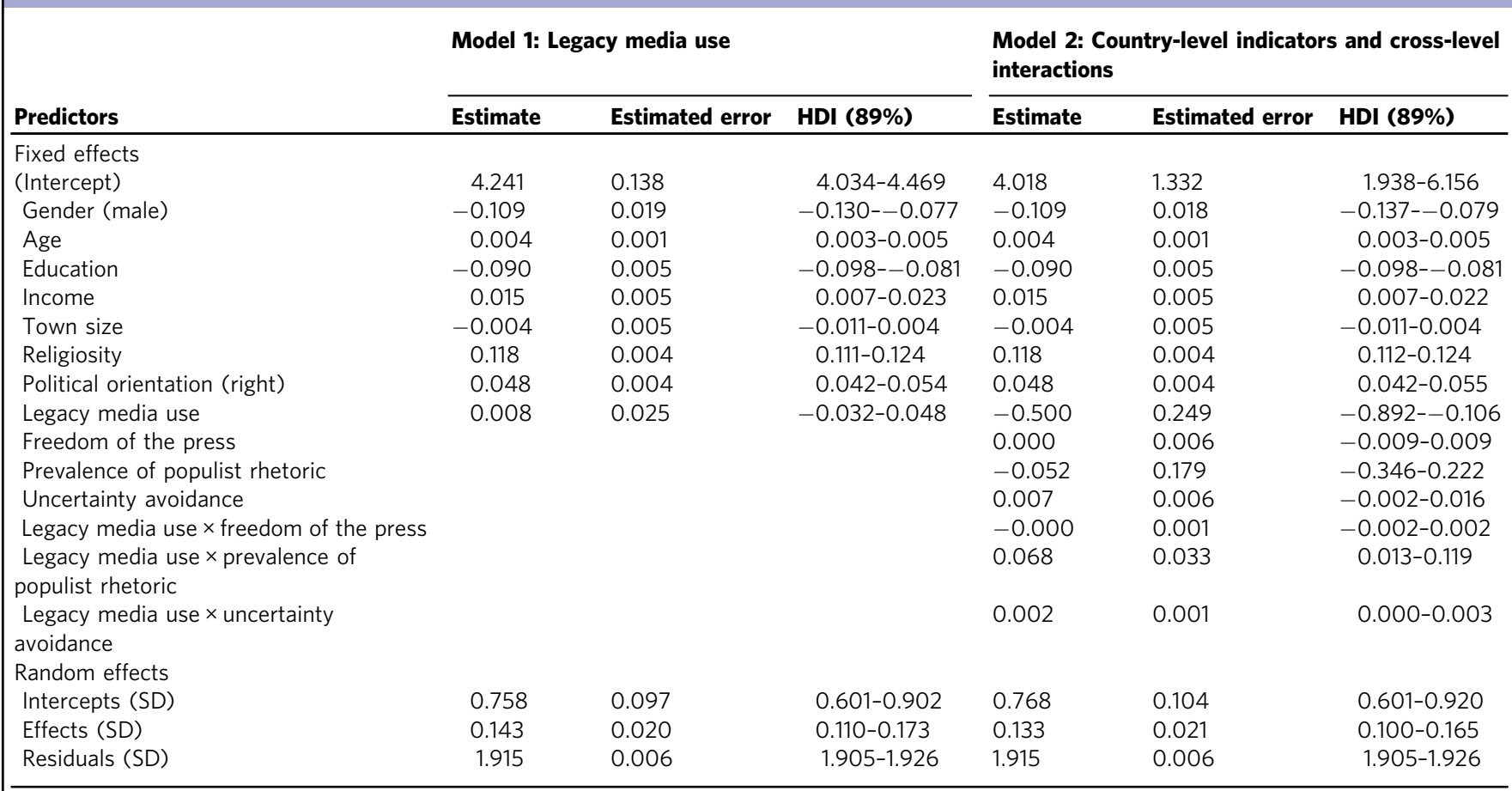

Note: Models contained country-level varying intercepts and slopes of media use. Models fitted using the R package brms v2.15.0 (Bürkner, 2021) and weakly informative priors (Nalborczyk et al., 2019). Observations $=44,055$, Levels $=38$. Model 1: Adjusted ICC $=0.140$, Conditional ICC $=0.133$, WAIC $=182,361.1(S E=293.0)$. Model 2: Adjusted ICC $=0.134$, Conditional ICC $=0.125$, WAIC $=$ $182,362.0(\mathrm{SE}=293.0)$

negative association between legacy media use and anti-science attitudes. Yet in line with most of this research, we did find that people are more likely to hold such attitudes if they are female, older, and lower educated, have fewer income, are more religious, or prefer right-leaning political positions (see Table 1, Model 1).

But in certain countries, people are indeed less likely to endorse anti-science attitudes if they use legacy media more often, for example in Thailand, Ethiopia, Nigeria, and the US (see Fig. 2). However, media use does not always undermine reservations against science-but can also exacerbate them: In countries like Turkey, Bangladesh, Cyprus, Bolivia, Serbia, or Peru, higher newspaper, TV, and radio use translates into stronger anti-science attitudes. Analyses also showed that $14 \%$ of the global variance of anti-science attitudes is due to country differences. Overall, we found limited support for $\mathrm{H} 1$, while we did find evidence for the varying media use effects that RQ2 assumed.

RQ3 analyses indicated that country differences in the association of media use and anti-science attitudes can be explained by differences in the prevalence of populist rhetoric in domestic political discourses: When including cross-level interactions between legacy media use and the three country-level indicators, we found that media use increases anti-science attitudes in countries with high prevalence of populist rhetoric, and decreases these attitudes in countries with low prevalence $(b=0.068,89 \%$ HDI: 0.013-0.119). Press freedom and uncertainty avoidance do not seem to have considerable impact on the relationship between media use and anti-science attitudes (see Table 1, Model 2).

\section{Discussion}

Public resentment toward science has been discussed as a major challenge to informed citizenries, societies' crisis resilience, and democratization worldwide (Flinders, 2021). Population surveys have therefore investigated the prevalence and explanatory factors of such resentment, and suggested it can be reduced through frequent use of legacy media (Anderson et al., 2012). However, these investigations offered limited evidence on the interplay of anti-science attitudes and media use in non-WEIRD countries. This study addressed this shortcoming, drawing on a secondary analysis of the World Values Survey 2017-2020.

Focusing on three components of anti-science attitudes-preference of faith over scientific expertise, moral reservations, and cognitive disengagement-we showed that public resentment toward science varies substantially across the world, but is generally more prevalent in several Latin American and less prevalent in most Anglo-American nations. This suggests that global variation in antiscience attitudes is partly due to sociopolitical and cultural factors: Perhaps populist governments in countries like Nicaragua, Bolivia, and Mexico have cultivated certain anti-scientific or anti-technocratic reservations among the population or got elected because they tapped existing reservations (Barrenechea and Dargent, 2020). Meanwhile, Australians and US Americans, for example, may rather subscribe to a "deference to scientific authority", i.e., an authoritarian-like socialized trait, which generates "an almost natural pro-science or protechnology view" (Brossard and Nisbet, 2007, p. 44).

However, anti-science attitudes do fluctuate among Latin American and among Anglo-American countries. This indicates that they are not necessarily associated with literacy, national wealth, democratic deficiency, or other heuristics for distinguishing between WEIRD and non-WEIRD societies (see Schlipphak et al., 2021). Rather, anti-science attitudes may often depend on specific local conditions: In Nigeria, for example, public perceptions of science were shown to result from a complex interaction of high trust in scientific institutions, strong religious beliefs, prominent promoters of conspiracy theories, and post-colonial resentment toward Western science (Falade, 2019; Falade and Bauer, 2018; Obadare and Okeke, 2011). After all, our analyses showed that country differences explain only a limited amount of variance of anti-science attitudes, while the majority of such variance is due to individual-level predictors such as gender, 


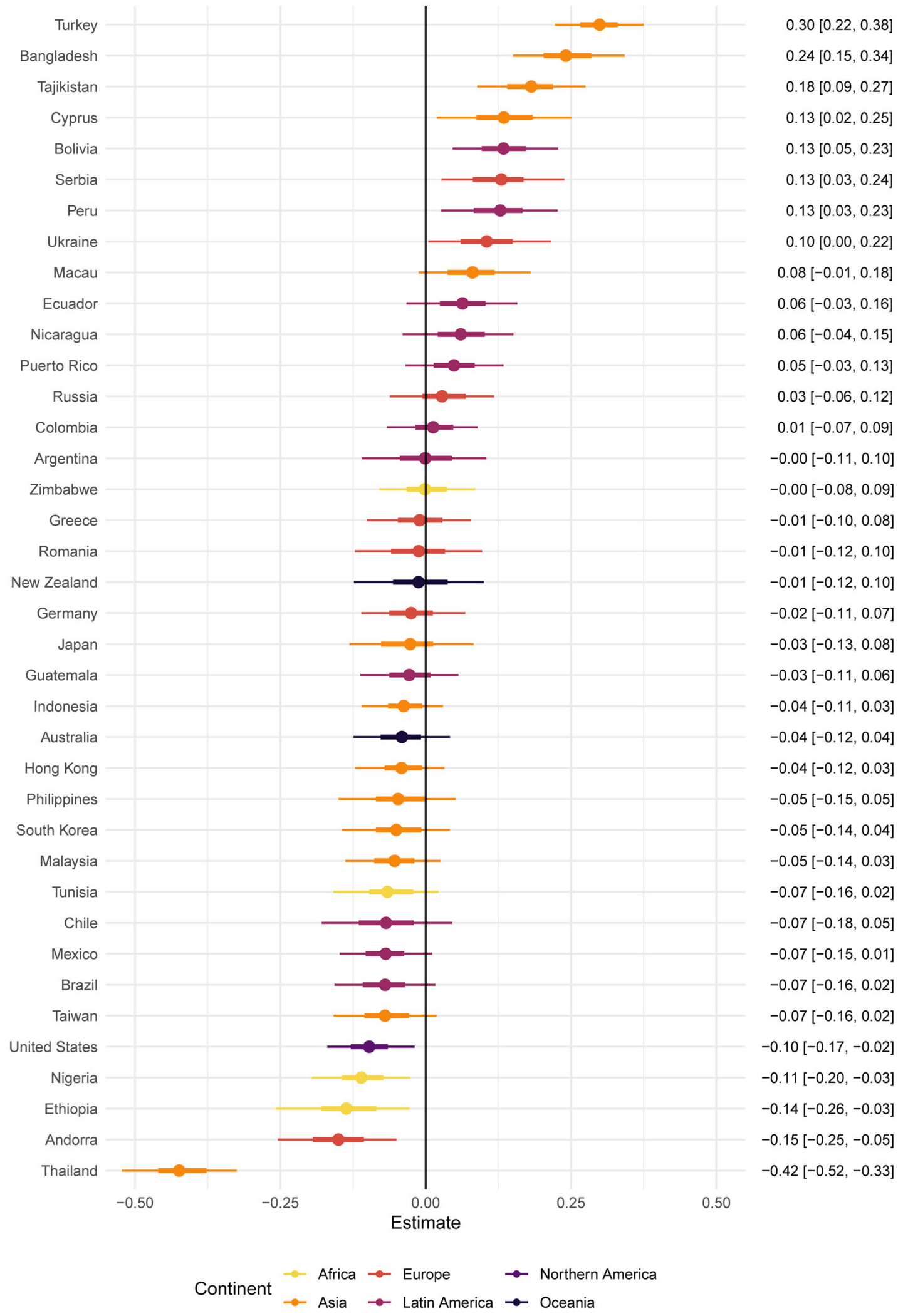

Fig. 2 Country-level effects of legacy media use on anti-science attitudes. Note: Points represent means of posterior probability distributions of varying slopes of media use (estimated with Bayesian multilevel regression, Model 1). Thin horizontal lines represent $89 \%$ HDIs. Thick horizontal lines represent $50 \%$ HDIs. Values indicate distribution means as well as lower and upper bounds of $89 \% \mathrm{HDIs}$.

age, education, income, religiosity, and political orientation. This confirms previous findings (European Commission, 2021; Wellcome Trust, 2019), and suggests that public resentment toward science is primarily a function of sociodemographic characteristics and individual worldviews rather than those country-level factors examined in this study.

Scholarship suggests that legacy media can reduce anti-science sentiment among their audience, as they cultivate positive views 
of science, educate citizens, and connect publics to science and scientific discourse. Our analyses did not provide support for this assumption in general, yet for specific nations like the US, Nigeria, and Thailand. In these countries, frequent use of newspapers, TV, and radio is indeed linked to less negative attitudes toward science. Perhaps media in these countries often promote pro-science views among their audiences, for example through positive portrayals and affirmative evaluations of scientific research (Besley and Shanahan, 2005; Liu and Priest, 2009; Nisbet et al., 2002). This result corresponds with existing research showing that legacy media use can strengthen trust in science and scientists (Anderson et al., 2012; Cacciatore et al., 2018; Hilgard and Jamieson, 2017). Increasing the reach of, and exposure to, legacy media may thus be a promising approach for science communication strategies aiming to temper public reservations against science-at least in many of the nations included in our analysis.

However, in countries like Turkey, Bangladesh, and Bolivia, legacy media use is not associated with weaker but stronger antiscience attitudes. Newspapers as well as radio and TV stations in these countries may not necessarily cultivate appreciation of scientific expertise and sympathy for scientists among their audiences. Instead, they might promote skeptical perspectives on science, emphasizing partisan cues (Kreps and Kriner, 2020) or failures of scientists (Ophir and Jamieson, 2021). Turkish newspaper coverage on genetic engineering, for example, has been shown to make frequent use of personal attacks on scientists and endorse a rather critical stance toward scientific institutions, "eventually leading to a decline in the authority of science" (Süerdem, 2019, p. 153).

While the style and slant of local media coverage may be one reason for country-specific media effects on anti-science attitudes, our study suggests an additional explanation-i.e., the prevalence of populist rhetoric in political discourse. Across all 38 nations included in the analysis, legacy media use was more likely to increase anti-science attitudes in countries where political parties frequently promote populist claims. Accordingly, legacy media seem to have worse chances to reduce reservations against science in publics perpetuated by populist discourse, and better chances in publics free from such discourse. This finding resonates with the results of previous WVS analyses, which suggested that political contexts condition the relationship of trust and media use (You and Wang, 2020). It could be explained in at least two ways: First, it might be that citizens who are often exposed to the rhetoric of populist parties develop skeptical attitudes toward legacy media and refrain from using them, because these parties often accuse legacy media of being deceitful, corrupt, and conspiring with a societal elite (Fawzi and Krämer, 2021). In consequence, legacy media would become limited in their ability to cultivate pro-science attitudes among the supporters of populist parties. Second, it might also be that legacy media themselves convey populist sentiment among their users when reporting about the claims of populist parties (Müller et al., 2017), thereby "normalizing" populist rhetoric (Katsourides and Pachita, 2021). Populist rhetoric often entails criticism of scientific expertise and the alleged "truth-speaking sovereignty [of] academic elites" (Mede and Schäfer, 2020, p. 482), so media audiences may then be more likely to adopt anti-science attitudes.

These dynamics possibly undermine the ability of legacy media to foster trust in science (Huber et al., 2019), connect the public to societal discourse around science (Schäfer, 2016), and provide citizens with "the best available evidence" for political and everyday decision-making (Scheufele and Krause, 2019, p. 7667). They seem to be particularly pronounced in Latin American countries like Bolivia and Peru as well as in Cyprus and Turkey, which drove the interaction effect of media use and populism on anti-science attitudes (see Fig. 2). On the one hand, this is plausible: In Bolivia, populist leaders like former president Evo Morales have publicly ostracized important academics and intellectuals (McKay and Colque, 2021), often leveraging government-controlled media outlets and news agencies (Waisbord, 2011). Meanwhile, Cyprus has seen a "mainstreaming" of populist and commonsensical rhetoric within political and media discourse (Katsourides and Pachita, 2021), which has potentially triggered, or resulted from, strong public anti-science resentment: Among all 27 countries surveyed for the Special Eurobarometer 2021, Cypriotes showed the strongest beliefs in conspiracy theories and least sympathy for scientists (European Commission, 2021). On the other hand, however, we did not find a link between populism, media use, and anti-science attitudes in countries where political rhetoric, news media coverage, and public attitudes are also pervaded by populist ideas, such as Romania (Chiruta, 2021; Corbu et al., 2017; Rutjens et al., 2022). This suggests that such a link, if existing, depends on factors that we did not analyze in this study.

One such factor could be people's use of digital media like social networking sites, instant messengers, or alternative news platforms (Huber et al., 2019; Mari et al., 2021; Yan et al., 2021). These media allow populists to circumvent presumed elite influence (Hopster, 2021) and provide them with a public arena (Jungherr and Schroeder, 2021) for supplying citizens with antiscientific claims-often reaching especially those users who already endorse these claims (see Schulz, 2019). Low press freedom may even fuel this dynamic, because citizens often rely on digital media when they suspect that legacy media are censored or slanted (Wei et al., 2014).

Overall, our analysis provides valuable findings on public reservations against science in WEIRD and non-WEIRD countries and the potential of legacy media to reduce or promote these reservations. Further research should scrutinize these findingsand seek to compensate their limitations: First, it could investigate the relationship of social media use and anti-science attitudes, as well as moderation effects of populism and press freedom.

Second, follow-up studies could tackle caveats of our legacy media use measurement: We aimed to investigate a general repertoire of traditional news media and thus relied on an aggregate score of newspaper, TV, and radio use. However, media use can vary considerably across different types of media (Newman et al., 2021). Future research should thus explore use of single legacy media specifically, include additional media channels such as magazines, or focus on science media use in particular. This would allow testing if the prevalence of populist rhetoric has stronger interaction effects among frequent TV viewers, for example, and weaker interaction effects among frequent quality newspaper readers, which would correspond with previous findings on news use and political populism (Schulz, 2019).

Third, further research could examine cultural and media contexts more thoroughly: Our study considered only one media context factor (i.e., freedom of the press), while there are many more, e.g., ownership concentration, Internet diffusion, or government regulation (Hallin and Mancini, 2011). The Freedom of the Press Index covers several of these factors and has been used frequently in related research (Coffé, 2017), hence we chose itbut we hope that future studies will incorporate further indicators. Such studies could also address caveats of the Uncertainty Avoidance Index, which reflects a contested concept and primarily relies on data that has been criticized for being dated and biased (Gerlach and Eriksson, 2021). For example, one could utilize refined uncertainty avoidance measurements or focus on related phenomena, such as risk aversion or anomie (see Achterberg et al., 2017). 
Fourth, follow-up research should also investigate causal links of legacy media use and anti-science attitudes: We modeled these attitudes as an outcome of media use, drawing on previous research and well-established theoretical assumptions. Yet media use may also be conceived as a function of anti-science attitudes (see Metag, 2020). As we relied on cross-sectional data, we could not test this-but we encourage experiments or panel studies to do so (see Merkley and Loewen, 2021).

Fifth, qualitative research may scrutinize semantic challenges to measuring anti-science attitudes, exploring what respondents understand as "science" (Koch et al., 2020) and whether their attitudes refer to academic institutions, scientific principles and methods, or science as whole (Achterberg et al., 2017). Eventually, findings of any such scholarship would call for further discussion of the societal status of science (Dahlgren, 2018) and implications for science communication practice (Schäfer and Metag, 2021).

\section{Data availability}

The code and data used in this study are available in the OSF repository, https://osf.io/w4gey.

Received: 6 September 2021; Accepted: 17 January 2022;

Published online: 02 February 2022

\section{Note}

1 Exceptions: Australia, Japan, New Zealand (postal interviews), Hong Kong, Malaysia (web-based and face-to-face interviews), and the United States (web-based and telephone interviews)

\section{References}

Achterberg P, de Koster W, van der Waal J (2017) A science confidence gap: education, trust in scientific methods, and trust in scientific institutions in the United States, 2014. Public Underst Sci 26(6):704-720. https://doi.org/ $10.1177 / 0963662515617367$

Adam S, Reber U, Häussler T, Schmid-Petri H (2020) How climate change skeptics (try to) spread their ideas: Using computational methods to assess the resonance among skeptics' and legacy media. PLoS One 15(10). https:// doi.org/10.1371/journal.pone.0240089

Alemán J, Woods D (2016) Value orientations from the World Values Survey: How comparable are they cross-nationally? Comp Polit Stud 49(8):1039-1067. https://doi.org/10.1177/0010414015600458

All European Academies (2019) Trust in science and changing landscapes of communication. ALLEA Discussion Paper \#3. https://www.allea.org/trust-inscience-in-a-digital-world-new-mechanisms-needed/. Accessed 14 Jan 2022

Allum N, Sturgis P, Tabourazi D, Brunton-Smith I (2008) Science knowledge and attitudes across cultures: a meta-analysis. Public Underst Sci 17(1):35-54. https://doi.org/10.1177/0963662506070159

Anderson AA, Scheufele DA, Brossard D, Corley EA (2012) The role of media and deference to scientific authority in cultivating trust in sources of information about emerging technologies. Int J Public Opin Res 24(2):225-237. https:// doi.org/10.1093/ijpor/edr032

Barrenechea R, Dargent E (2020) Populists and technocrats in Latin America: conflict, cohabitation, and cooperation. Politics Gov 8(4):509-519. https:// doi.org/10.17645/pag.v8i4.3333

Bauer M, Süerdem A (2016) Relating 'science culture' and innovation. OECD Blue Sky Forum on Science and Innovation Indicators 2016, 19-21 September 2016, Ghent, Belgium, http://eprints.lse.ac.uk/67933/. Accessed 14 Jan 2022

Bauer MW, Pansegrau P, Shukla R (eds.) (2019) The cultural authority of science: Comparing across Europe, Asia, Africa, and the Americas. Routledge, London

Besley JC, Shanahan J (2005) Media attention and exposure in relation to support for agricultural biotechnology. Sci Commun 26(4):347-367. https://doi.org/ $10.1177 / 1075547005275443$

Bollen KA (1980) Issues in the comparative measurement of political democracy. Am Sociol Rev 45(3):370. https://doi.org/10.2307/2095172

Boomgaarden H, Song H (2019) Media use and its effects in a cross-national perspective. Kolner Z Soz Sozpsychol 71(S1):545-571. https://doi.org/ 10.1007/s11577-019-00596-9

Brondi S et al. (2021) Dimensions of trust in different forms of science communication: the role of information sources and channels used to acquire science knowledge. J Sci Commun 20(3). https://doi.org/10.22323/2.20030208
Brossard D, Nisbet MC (2007) Deference to scientific authority among a low information public: understanding U.S. opinion on agricultural biotechnology. Int J Public Opin Res 19(1):24-52. https://doi.org/10.1093/ijpor/ edl003

Bürkner P-C (2021) brms: Bayesian regression models using 'Stan'. R package version 2.15.0. https://cran.r-project.org/web/packages/brms

Cacciatore MA et al. (2018) Opposing ends of the spectrum: exploring trust in scientific and religious authorities. Public Underst Sci 27(1):11-28. https:// doi.org/10.1177/0963662516661090

Chan E (2018) Are the religious suspicious of science? Investigating religiosity, religious context, and orientations towards science. Public Underst Sci 27(8):967-984. https://doi.org/10.1177/0963662518781231

Chiruta I (2021) Challenging the rule of law in Romania: the metamorphosis of political discourse towards populism. Probl Post-Communism. https:// doi.org/10.1080/10758216.2021.1958690

Coffé H (2017) Citizens' media use and the accuracy of their perceptions of electoral integrity. Int Political Sci Rev 38(3):281-297. https://doi.org/ $10.1177 / 0192512116640984$

Corbu N, Balaban-Bălaş D, Negrea-Busuioc E (2017) Romania: populist ideology without teeth. In: Aalberg T, et al. (eds.) Populist political communication in Europe. Routledge, London, p 326-338

Crettaz von Roten F (2019) Attitudes towards science in the World Values Surveys - longitudinal evidence 1981-2014. In: Bauer MW, Pansegrau P, Shukla R (eds.) The cultural authority of science: comparing across Europe, Asia, Africa, and the Americas. Routledge, London, pp. 264-277

Curtice J (2007) Comparative opinion surveys. In: Dalton RJ, Klingemann H-D (eds.) The Oxford Handbook of Political Behavior. Oxford University Press

Dahlgren P (2018) Media, knowledge and trust: the deepening epistemic crisis of democracy. Javnost 25(1-2):20-27. https://doi.org/10.1080/13183222.2018. 1418819

Diehl T, Huber B, Gil de Zúñiga H, Liu J (2021) Social media and beliefs about climate change: a cross-national analysis of news use, political ideology, and trust in science. Int J Public Opin Res 33(2):197-213. https://doi.org/10.1093/ ijpor/edz040

Drori GS, Meyer JW, Ramirez FO, Schofer E (2003) Science in the modern world polity: institutionalization and globalization. Stanford University Press, Stanford

Dudo A et al. (2011) Science on television in the $21^{\text {st }}$ century: recent trends in portrayals and their contributions to public attitudes toward science. Com munic Res 38(6):754-777. https://doi.org/10.1177/0093650210384988

Esmer Y (2004) Cross-cultural comparisons, survey methodology and the values surveys. In: Inglehart R, et al. (eds.) Human beliefs and values: a crosscultural sourcebook based on the 1999-2002 values surveys. Siglo XXI Editores, Mexico, p 385-397

European Commission (2021) European citizens' knowledge and attitudes towards science and technology: special Eurobarometer 516. https://europa.eu/ eurobarometer/surveys/detail/2237 Accessed 14 Jan 2022

Evans G, Durant J (1995) The relationship between knowledge and attitudes in the public understanding of science in Britain. Public Underst Sci 4(1):57-74. https://doi.org/10.1088/0963-6625/4/1/004

Evans JH (2014) Faith in science in global perspective: implications for transhumanism. Public Underst Sci 23(7):814-832. https://doi.org/10.1177/ 0963662514523712

Falade BA (2019) Vaccines Polio and Ebola: religion and traditions compete with scientific authority in West Africa. In: Bauer MW, Pansegrau P, Shukla R (eds.) The cultural authority of science: comparing across Europe, Asia, Africa, and the Americas. Routledge, London, p 211-227

Falade BA, Bauer MW (2018) 'I have faith in science and in God': common sense, cognitive polyphasia and attitudes to science in Nigeria. Public Underst Sci 27(1):29-46. https://doi.org/10.1177/0963662517690293

Fawzi N, Krämer B (2021) The media as part of a detached elite? Exploring antimedia populism among citizens and its relation to political populism. Int J Commun 15:3292-3314

Flinders M (2021) Democracy and the politics of Coronavirus: trust, blame and understanding. Parliam Aff 74(2):483-502. https://doi.org/10.1093/pa/ gsaa013

Forchtner B, Kroneder A, Wetzel D (2018) Being skeptical?: exploring far-right climate-change communication in Germany. Environ Commun 12(5):589-604. https://doi.org/10.1080/17524032.2018.1470546

Franzen A, Meyer R (2010) Environmental attitudes in cross-national perspective: a multilevel analysis of the ISSP 1993 and 2000. Eur Sociol Rev 26(2):219-234. https://doi.org/10.1093/esr/jcp018

Freedom House (2021) Freedom of the press research methodology. https:// freedomhouse.org/freedom-press-research-methodology Accessed 14 Jan 2022

Freudenberg M (2003) Composite indicators of country performance: a critical assessment. OECD Science, Technology and Industry Working Papers 2003/ 16, Paris 
Gerlach P, Eriksson K (2021) Measuring cultural dimensions: external validity and internal consistency of Hofstede's VSM 2013 scales. Front Psychol 12. https:// doi.org/10.3389/fpsyg.2021.662604

Gil de Zúñiga $\mathrm{H}$ et al. (2019) Trust in institutional actors across 22 countries: Examining political, science, and media trust around the world. Rev Lat de Comun Soc 74:237-262

Guenther L, Joubert M (2017) Science communication as a field of research: identifying trends, challenges and gaps by analysing research papers. J Sci Commun 16(2). https://doi.org/10.22323/2.16020202

Guenther L, Weingart P (2018) Promises and reservations towards science and technology among South African publics: a culture-sensitive approach. Public Underst Sci 27(1):47-58. https://doi.org/10.1177/0963662517693453

Haerpfer C et al. (2020) World Values Survey Wave 7 (2017-2020) Cross-National Data-Set. https://doi.org/10.14281/18241.1

Haerpfer C, Kizilova K (2017) The World Values Survey. In: Ritzer G (ed.) The Wiley-Blackwell Encyclopedia of Globalization. John Wiley \& Sons, Chichester

Hallin DC, Mancini P (2011) Comparing media systems beyond the Western world. Cambridge University Press, Cambridge

Heath A, Fisher S, Smith S (2005) The globalization of public opinion research. Annu Rev Polit Sci 8(1):297-333. https://doi.org/10.1146/annurev.polisci. 8.090203 .103000

Hilgard J, Jamieson KH (2017) Does a scientific breakthrough increase confidence in science? News of a Zika vaccine and trust in science. Sci Commun 39(4):548-560. https://doi.org/10.1177/1075547017719075

Hmielowski JD et al. (2014) An attack on science? Media use, trust in scientists, and perceptions of global warming. Public Underst Sci 23(7):866-883. https://doi.org/10.1177/0963662513480091

Hofstede G (1980) Culture's consequences: International differences in workrelated values. Sage, Newbury Park

Hofstede G, Hofstede GJ, Minkov M (2010) Cultures and organizations: software of the mind, 3rd edn. McGraw-Hill, New York, NY

Hopster J (2021) Mutual affordances: the dynamics between social media and populism. Media, Culture \& Society 43(3):551-560. https://doi.org/10.1177/ 0163443720957889

Hornsey MJ, Harris EA, Fielding KS (2018a) Relationships among conspiratorial beliefs, conservatism and climate scepticism across nations. Nat Clim Chang 8(7):614-620. https://doi.org/10.1038/s41558-018-0157-2

Hornsey MJ, Harris EA, Fielding KS (2018b) The psychological roots of antivaccination attitudes: A 24-nation investigation. Health Psychol 37(4):307-315. https://doi.org/10.1037/hea0000586

Huber B, Barnidge M, Gil de Zúñiga H, Liu J (2019) Fostering public trust in science: the role of social media. Public Underst Sci 28(7):759-777. https:// doi.org/10.1177/0963662519869097

Inglehart R et al. (eds.) (2004) Human beliefs and values: a cross-cultural sourcebook based on the 1999-2002 values surveys. Siglo XXI Editores, Mexico

Johnson ND, Mislin A (2012) How much should we trust the World Values Survey trust question? Econ Lett 116(2):210-212. https://doi.org/10.1016/ j.econlet.2012.02.010

Jungherr A, Schroeder R (2021) Disinformation and the structural transformations of the public arena: addressing the actual challenges to democracy. Soc Media Soc 7(1). https://doi.org/10.1177/2056305121988928

Kam CD (2005) Who toes the party line? Cues, values, and individual differences. Polit Behav 27(2):163-182. https://doi.org/10.1007/s11109-0051764-y

Katsourides Y, Pachita EK (2021) Normalizing far right party rhetoric: the impact of media populist frames and coverage on the electoral prospects of far-right parties in the case of Cyprus. J Contemp Eur Res. https://doi.org/10.1080/ 14782804.2021 .1951184

Kim Y, Kim M, Kim W (2013) Effect of the Fukushima nuclear disaster on global public acceptance of nuclear energy. Energy Policy 61:822-828. https:// doi.org/10.1016/j.enpol.2013.06.107

Kim S, Choi S-O, Wang J (2014) Individual perception vs. structural context: searching for multilevel determinants of social acceptance of new science and technology across 34 countries. Sci Public Policy 41(1):44-57. https://doi.org/ $10.1093 / \mathrm{scipol} / \mathrm{sct} 032$

Koch C et al. (2020) "Space means Science, unless it's about Star Wars": a qualitative assessment of science communication audience segments. Public Underst Sci 29(2):157-175. https://doi.org/10.1177/0963662519881938

Kreps SE, Kriner DL (2020) Model uncertainty, political contestation, and public trust in science: evidence from the COVID-19 pandemic. Sci Adv 6(43). https://doi.org/10.1126/sciadv.abd4563

Lee C-J, Scheufele DA (2006) The influence of knowledge and deference toward scientific authority: a media effects model for public attitudes toward nanotechnology. Journal Mass Commun Q 83(4):819-834. https://doi.org/ 10.1177/107769900608300406

Lewicki RJ, McAllister DJ, Bies RJ (1998) Trust and distrust: New relationships and realities. AMR 23(3):438-458. https://doi.org/10.5465/amr.1998.926620
Liu H, Priest S (2009) Understanding public support for stem cell research: media communication, interpersonal communication and trust in key actors. Public Underst Sci 18(6):704-718. https://doi.org/10.1177/0963662508097625

Lübke C (2021) Socioeconomic roots of climate change denial and uncertainty among the European population. Eur Sociol Rev. https://doi.org/10.1093/esr/ jcab035

Luna DS, Bering JM, Halberstadt JB (2021) Public faith in science in the United States through the early months of the COVID-19 pandemic. Public Health in Practice. https://doi.org/10.1016/j.puhip.2021.100103

Mari S et al. (2021) Conspiracy theories and institutional trust: Examining the role of uncertainty avoidance and active social media use. Polit Psychol. https:// doi.org/10.1111/pops.12754

Marsh HW et al. (2011) Methodological measurement fruitfulness of exploratory structural equation modeling (ESEM): New approaches to key substantive issues in motivation and engagement. J Psychoeduc Assess 29(4):322-346. https://doi.org/10.1177/0734282911406657

Massarani L (2015) Voices from other lands. Public Underst Sci 24(1):2-5. https:// doi.org/10.1177/0963662514563888

McElreath R (2020) Statistical rethinking: A Bayesian course with examples in R and Stan, 2nd edn. Chapman \& Hall, Boca Raton

McKay BM, Colque G (2021) Populism and its authoritarian tendencies: The politics of division in Bolivia. Lat Am Perspect. https://doi.org/10.1177/ 0094582X211052980

Mede NG, Schäfer MS (2020) Science-related populism: Conceptualizing populist demands toward science. Public Underst Sci 29(5):473-491. https://doi.org/ $10.1177 / 0963662520924259$

Mede NG, Schäfer MS, Füchslin T (2021) The SciPop Scale for measuring sciencerelated populist attitudes in surveys: Development, test, and validation. Int J Public Opin Res 33(2):273-293. https://doi.org/10.1093/ijpor/edaa026

Mehta G, Hopf H, Krief A, Matlin SA (2020) Realigning science, society and policy in uncertain times. R Soc Open Sci 7(5). https://doi.org/10.1098/rsos.200554

Merkley E, Loewen PJ (2021) Anti-intellectualism and the mass public's response to the COVID-19 pandemic. Nat Hum Behav 5(6):706-715. https://doi.org/ $10.1038 / \mathrm{s} 41562-021-01112-\mathrm{w}$

Metag J (2020) What drives science media use? Predictors of media use for information about science and research in digital information environments. Public Underst Sci 29(6):561-578. https://doi.org/10.1177/0963662520935062

Metag J, Schäfer MS (2018) Audience segments in environmental and science communication: Recent findings and future perspectives. Environ Commun 12(8):995-1004. https://doi.org/10.1080/17524032.2018.1521542

Miller JD (2004) Public understanding of, and attitudes toward, scientific research: What we know and what we need to know. Public Underst Sci 13(3):273-294. https://doi.org/10.1177/0963662504044908

Motta M (2018) The dynamics and political implications of anti-intellectualism in the United States. Am Politics Res 46(3):465-498. https://doi.org/10.1177/ $1532673 X 17719507$

Müller P et al. (2017) The polarizing impact of news coverage on populist attitudes in the public: Evidence from a panel study in four European democracies. J Commun 67(6):968-992. https://doi.org/10.1111/jcom.12337

Nalborczyk L et al. (2019) An introduction to Bayesian multilevel models using brms: A case study of gender effects on vowel variability in standard Indonesian. J Speech Lang Hear Res 62(5):1225-1242. https://doi.org/10.1044/ 2018_JSLHR-S-18-0006

Newman N et al. (2021) Reuters Institute Digital News Report 2021. https:// reutersinstitute.politics.ox.ac.uk/sites/default/files/2021-06/Digital_News_ Report_2021_FINAL.pdf Accessed 14 Jan 2022

an Nguyen, Tran M (2019) Science journalism for development in the Global South: A systematic literature review of issues and challenges. Public Underst Sci 28(8):973-990. https://doi.org/10.1177/0963662519875447

Nisbet M et al. (2002) Knowledge, reservations, or promise? A media effects model for public perceptions of science and technology. Communic Res 29(5):584-608. https://doi.org/10.1177/009365002236196

Norris P (2020) Measuring populism worldwide. Party Politics 26(6):697-717. https://doi.org/10.1177/1354068820927686

Norris P, Inglehart R (2019) Cultural backlash: Trump, Brexit, and authoritarian populism. Cambridge University Press, Cambridge

Noy S, O'Brien TL (2019) Science for good? The effects of education and national context on perceptions of science. Public Underst Sci 28(8):897-916. https:// doi.org/10.1177/0963662519863575

Obadare E, Okeke IN (2011) Biomedical loopholes, distrusted state, and the politics of HIV/AIDS "cure" in Nigeria. Afr Aff 110(439):191-211. https://doi.org/ 10.1093/afraf/adr001

O'Brien TL, Noy S (2018) Cultural authority in comparative context: A multilevel analysis of trust in science and religion. J Sci Study Relig 57(3):495-513. https://doi.org/10.1111/jssr.12537

Ophir Y, Jamieson KH (2021) The effects of media narratives about failures and discoveries in science on beliefs about and support for science. Public Underst Sci 30(8):1008-1023. https://doi.org/10.1177/09636625211012630 
Price AM, Peterson LP (2016) Scientific progress, risk, and development: Explaining attitudes toward science cross-nationally. Int Sociol 31(1):57-80. https://doi.org/10.1177/0268580915614593

Ruan Y, Yang J, Jin J (2019) One issue, different stories: The construction of GMO issues on Chinese, American and British mainstream media portals. Cult Sci 2(4):255-275. https://doi.org/10.1177/209660831900200403

Rutjens BT et al. (2022) Science skepticism across 24 countries. Soc Psychol Personal Sci 13(1):102-117. https://doi.org/10.1177/19485506211001329

Schäfer MS (2016) Mediated trust in science: concept, measurement and perspectives for the 'science of science communication'. J Sci Commun 15(5). https://doi.org/10.22323/2.15050302

Schäfer MS, Metag J (2021) Audiences of science communication between pluralization, fragmentation and polarization. In: Bucchi M, Trench B (eds.) Handbook of public communication of science and technology. Routledge, London

Scharkow M (2019) The reliability and temporal stability of self-reported media exposure: A meta-analysis. Commun Methods Meas 13(3):198-211. https:// doi.org/10.1080/19312458.2019.1594742

Scheufele DA, Krause NM (2019) Science audiences, misinformation, and fake news. Proc Natl Acad Sci USA 116(16):7662-7669. https://doi.org/10.1073/ pnas. 1805871115

Schlipphak B, Bollwerk M, Back M (2021) Beliefs in conspiracy theories (CT): The role of country context. Political Res Exch 3(1). https://doi.org/10.1080/ 2474736X.2021.1949358

Schriesheim CA, Eisenbach RJ (1995) An exploratory and confirmatory factoranalytic investigation of item wording effects on the obtained factor structures of survey questionnaire measures. J Manage 21(6):1177-1193. https:// doi.org/10.1177/014920639502100609

Schulz A (2019) Where populist citizens get the news: An investigation of news audience polarization along populist attitudes in 11 countries. Commun Monogr 86(1):88-111. https://doi.org/10.1080/03637751.2018.1508876

Smith PB, Peterson MF, Schwartz SH (2002) Cultural values, sources of guidance, and their relevance to managerial behavior. J Cross Cult Psychol 33(2):188-208. https://doi.org/10.1177/0022022102033002005

Solís Arce JS et al. (2021) COVID-19 vaccine acceptance and hesitancy in low- and middle-income countries. Nat Med 27:1385-1394. https://doi.org/10.1038/ s41591-021-01454-y

Sturgis P, Brunton-Smith I, Jackson J (2021) Trust in science, social consensus and vaccine confidence. Nat Hum Behav. https://doi.org/10.1038/s41562-021-01115-7

Süerdem A (2019) Science news in Turkey: Data mining techniques for science culture mapping. In: Bauer MW, Pansegrau P, Shukla R (eds.) The cultural authority of science: Comparing across Europe, Asia, Africa, and the Americas. Routledge, London, p 136-154

Taber KS (2018) The use of Cronbach's Alpha when developing and reporting research instruments in science education. Res Sci Educ 48(6):1273-1296. https://doi.org/10.1007/s11165-016-9602-2

Thornborrow J, Ekstrom M, Patrona M (2021) Discursive constructions of populism in opinion-based journalism: A comparative European study. Discourse, Context Media 44. https://doi.org/10.1016/j.dcm.2021.100542

Tsfati Y, Ariely G (2014) Individual and contextual correlates of trust in media across 44 countries. Communic Res 41(6):760-782. https://doi.org/10.1177/ 0093650213485972

Valkenburg PM, Peter J (2013) The differential susceptibility to media effects model. J Commun 63(2):221-243. https://doi.org/10.1111/jcom.12024

van de Walle S, Six F (2014) Trust and distrust as distinct concepts: Why studying distrust in institutions is important. J Comp Policy Anal: Res Pract 16(2):158-174. https://doi.org/10.1080/13876988.2013.785146

Waisbord S (2011) Between support and confrontation: Civic society, media reform, and populism in Latin America. Commun Cult Crit 4(1):97-117. https://doi.org/10.1111/j.1753-9137.2010.01095.x

Wei R et al. (2014) Predicting mobile news use among college students: The role of press freedom in four Asian cities. New Media Soc 16(4):637-654. https:// doi.org/10.1177/1461444813487963
Wellcome Trust (2019) Wellcome Global Monitor 2018: How does the world feel about science and health? https://wellcome.org/reports/wellcome-globalmonitor/2018 Accessed 14 Jan 2022

Wettstein $\mathrm{M}$ et al. (2018) News media as gatekeepers, critics, and initiators of populist communication: How journalists in ten countries deal with the populist challenge. Int J Press Polit 23(4):476-495. https://doi.org/10.1177/ 1940161218785979

Yan P, Schroeder R, Stier S (2021) Is there a link between climate change scepticism and populism? An analysis of web tracking and survey data from Europe and the US. Inf Commun Soc. https://doi.org/10.1080/ 1369118X.2020.1864005

You Y, Wang Z (2020) The Internet, political trust, and regime types: A crossnational and multilevel analysis. Jpn J Political Sci 21(2):68-89. https:// doi.org/10.1017/S1468109919000203

\section{Acknowledgements}

I am grateful to Timothy O'Brien and Daniela Mahl, who reviewed an earlier version of the article and provided valuable feedback and many helpful ideas. I also thank Nick Allum, Martin Bauer, John Besley, Adrian Rauchfleisch, and Mike S. Schäfer, whose thorough comments on the conceptualization and the statistical analyses of this study have improved it considerably.

\section{Competing interests}

The author declares no competing interests.

\section{Ethical approval}

This article does not contain any studies with human participants or animals performed by the authors. Ethical approval was therefore not provided.

\section{Informed consent}

Informed consent for participation was not required for this study in accordance with the national legislation and institutional requirements.

\section{Additional information}

Supplementary information The online version contains supplementary material available at https://doi.org/10.1057/s41599-022-01058-y.

Correspondence and requests for materials should be addressed to Niels G. Mede.

Reprints and permission information is available at http://www.nature.com/reprints

Publisher's note Springer Nature remains neutral with regard to jurisdictional claims in published maps and institutional affiliations.

(c) (i) Open Access This article is licensed under a Creative Commons Attribution 4.0 International License, which permits use, sharing, adaptation, distribution and reproduction in any medium or format, as long as you give appropriate credit to the original author(s) and the source, provide a link to the Creative Commons license, and indicate if changes were made. The images or other third party material in this article are included in the article's Creative Commons license, unless indicated otherwise in a credit line to the material. If material is not included in the article's Creative Commons license and your intended use is not permitted by statutory regulation or exceeds the permitted use, you will need to obtain permission directly from the copyright holder. To view a copy of this license, visit http://creativecommons.org/ licenses/by/4.0/.

(C) The Author(s) 2022 